\title{
Synaptic Dysfunction in Alzheimer's Disease and Glaucoma: From Common Degenerative Mechanisms Toward Neuroprotection
}

\author{
Chiara Criscuolo ${ }^{1}$, Carlotta Fabiani ${ }^{1}$, Elisa Cerri ${ }^{1}$ and Luciano Domenici ${ }^{1,2 *}$ \\ ${ }^{1}$ Neuroscience Institute of the National Council of Research (CNR), Pisa, Italy, ${ }^{2}$ Department of Biotechnological and Applied \\ Clinical Sciences (DISCAB), University of L'Aquila, L'Aquila, Italy
}

Alzheimer's disease (AD) and glaucoma are two distinct multifactorial neurodegenerative diseases, primarily affecting the elderly. Common pathophysiological mechanisms have been elucidated in the past decades. First of all both diseases are progressive, with $A D$ leading to dementia and glaucoma inducing blindness. Pathologically, they all feature synaptic dysfunction with changes of neuronal circuitry, progressive accumulation of protein aggregates such as the beta amyloid $(A \beta)$ and intracellular microtubule inclusions containing hyperphosphorylated tau, which belongs to microtubule associated protein family. During an early phase of degeneration, both diseases are characterized by synaptic dysfunction and changes of mitogen-activated protein kinases (MAPK). Common degenerative mechanisms underlying both diseases are discussed here, along with recent results on the potential use of the visual system as a biomarker for diagnosis

OPEN ACCESS

Edited by:

Daniela Tropea,

Trinity College, Dublin, Ireland

Reviewed by: Mario Buffelli,

University of Verona, Italy Aline Stephan, University of Strasbourg, France Claudia Perez-Cruz, Centro de Investigaciones y Estudios Avanzados (CINVESTAV), Mexico

*Correspondence: Luciano Domenici domenici@in.cnr.it

Received: 04 October 2016 Accepted: 14 February 2017 Published: 27 February 2017

Citation:

Criscuolo C, Fabiani C, Cerri E and Domenici L (2017) Synaptic Dysfunction in Alzheimer's Disease and Glaucoma: From Common Degenerative Mechanisms Toward Neuroprotection.

Front. Cell. Neurosci. 11:53. doi: 10.3389/fncel.2017.00053 and progression of AD. Common neuropathological changes and mechanisms in AD and glaucoma have facilitated the transfer of therapeutic strategies between diseases. In particular, we discuss past and present evidence for neuroprotective effects of brainderived neurotrophic factor (BDNF).

Keywords: beta amyloid, tau, synaptic dysfunction, visual system impairment, brain-derived neurotrophic factor

\section{INTRODUCTION}

Alzheimer's disease $(\mathrm{AD})$ is a neurodegenerative progressive disease of the elderly leading to dementia. The world Alzheimer report (Alzheimer's Disease International) of 2015 indicated that 46.8 million people worldwide are living with dementia; this number is expected to double every 20 years (Reitz and Mayeux, 2014). There are two forms of AD.

1. Early onset familial alzheimer disease (eFAD). Abnormalities of the amyloid precursor protein (APP) that render it more amyloidogenic, or defects of processing normal APP cause genetic forms of $\mathrm{AD}$. The literature estimates that eFAD accounts for approximately $2 \%$ of all people with dementia (approximately 3\%-5\% of all Alzheimer cases; Mayeux and Stern, 2012; Tanzi, 2012). In these patients, autosomal dominant $A D$ usually develops before age 65 due to mutations of the APP gene on chromosome 21 or the presenilin 1 and 2 genes (PSEN1 and PSEN2) on chromosomes 14 and 1, respectively.

2. Sporadic AD (SAD, Late-Onset). SAD is very common in the elderly (approximately $70 \%$ of patients with dementia are attributed to SAD; Reitz and Mayeux, 2014). The cause of SAD is unknown. The vast majority of SAD is not genetically inherited although some genes such as the APOE may act as a major risk factor (Liu et al., 2013). 
Vascular diseases such as hypertension and brain ischemia (Pluta et al., 2013; Origlia et al., 2014), diabetes (Zhao et al., 2008; Adzovic and Domenici, 2014), traumatic brain injury (Van Den Heuvel et al., 2007) and mood disorders (Tsuno and Homma, 2009) represent risk factors for SAD; the most important risk factor for $\mathrm{SAD}$ is aging. Neuropathological changes of $\mathrm{AD}$ include classical hallmarks such as the senile plaques formed by beta amyloid (A $\beta$ ), neurofibrillary tangles (NFTs) and dystrophic neurites containing hyperphosphorylated tau (Serrano-Pozo et al., 2011). Histopathological findings showed that the entorhinal cortex and hippocampus are affected during the earliest phases of AD (Braak and Braak, 1991, 1993). Recent studies have highlighted an apparent dichotomy between the progress of histopathological findings in different brain areas and the occurrence of visual dysfunctions in $\mathrm{AD}$ (Moschos et al., 2012; Sivak, 2013; Yamasaki et al., 2016). More than $60 \%$ of people with $\mathrm{AD}$ have a decline in one or more visual function(s). AD causes vision impairment by affecting the eye (Graw, 2015) and by deterioration of visual functions, from retina to visual cortex. In particular, clinical studies support a link between cognitive performance and visual dysfunction even at an early stage of $\mathrm{AD}$; the gradual loss of memory is frequently accompanied by alteration of visuospatial function in animal models and AD patients (Rizzo et al., 2000; Crow et al., 2003). Recently, we showed an impairment of the visual responses arising from the magnocellular streams of visual processing (Sartucci et al., 2010), suggesting that large retinal ganglion cells (RGCs) are primarily affected in AD. Often, retinal involvement is an early occurrence in AD (Sivak, 2013) as also suggested by results obtained by the use of ocular imaging techniques such as the optical coherence tomography (Moschos et al., 2012).

Glaucoma is a group of eye disorders, currently recognized to be multifactorial and progressive, leading to reduction in vision and eventual blindness. Usually glaucoma affects the older population. Over 60 million people worldwide were estimated to be affected with glaucoma, and bilateral blindness from the disease was estimated to be present in 4.5 million people with glaucoma (Quigley and Broman, 2006). Glaucoma is characterized by the progressive degeneration of RGCs till cell death, optic nerve (ON) atrophy, impairment of visual function with visual field defects and finally, loss of neurons in the lateral geniculate nucleus and primary visual cortex. A generally accepted theory suggests an initial insult to the axons of RGCs in the ON head region (Quigley, 2011). Several types of glaucoma are known; these can be divided in primary and secondary. Primary open-angle glaucoma (POAG) is considered to be the most common subtype of glaucoma. There are two main types of POAG: one that occurs with an intraocular pressure (IOP) higher than normal and represents 60\%-70\% of the total POAG (Coleman and Brigatti, 2001; Quigley and Broman, 2006) and the other occurring with a normal or lower IOP. Thus, ocular hypertension represents the major risk factor for glaucoma onset and progression. In the presence of ocular hypertension, there is no obvious damage to the RGCs and ON or evidence of visual field changes. However, we recently showed that retinal responses to patterned visual stimuli (pattern electroretinogram, P-ERG) together with Brn3 (POU-domain transcription factor) expressed in RGCs are altered during ocular hypertension in a murine model of glaucoma (Domenici et al., 2014). It is reasonable to think that ocular hypertension applies some stress to RGCs and their circuitry during a phase preceding the degeneration of RGCs and ON atrophy.

\section{COMMON FEATURES BETWEEN AD AND GLAUCOMA}

Both diseases affect older populations and are neurodegenerative, chronic and progressive leading to irreversible cell death. AD and glaucoma are thought to share, at least in part, some common features such as the $\mathrm{A} \beta$ accumulation/aggregation, tau aggregation and hyperphosphorylation. Both diseases are characterized by early changes of neuronal circuitry and phosphorylation of mitogen-activated protein kinases (MAPK) followed by inflammatory process, glial reaction, reactive oxygen species production, oxidative stress and mitochondrial abnormalities, propagation of neurodegenerative processes leading to cell death. Both diseases are characterized by common features such as synaptic dysfunction and neuronal cell death at the level of the inner retina (Sartucci et al., 2010; Sivak, 2013). Taken together, all these observations suggest similar degenerative mechanisms between $\mathrm{AD}$ and glaucoma. Glaucoma is recognized as a disease frequently associated with $\mathrm{AD}$ and aging (Martinez et al., 1982; Chandra et al., 1986; Tamura et al., 2006; Tsolaki et al., 2011; Jefferis et al., 2013; Elyashiv et al., 2014). Conflicting data have been reported among the different studies carried out to compare AD frequency in glaucoma patients (Kessing et al., 2007; Yochim et al., 2012). Thus, a clear epidemiologic relationship between glaucoma and AD remains elusive.

\section{AMYLOID-DEPENDENT MECHANISMS IN AD AND GLAUCOMA}

Senile plaques in $\mathrm{AD}$ comprise aggregates of $\mathrm{A} \beta$ filaments, dystrophic neurites and mitochondrial abnormalities (Hirai et al., 2001; Serrano-Pozo et al., 2011). A $\beta$ peptides start to be generated in considerable amounts by the cleavage of APP due to sequential activation of $\beta$ - and presenilin catalytic site of $\gamma$-secretases. $A \beta$ can be found in different compositions of monomers, oligomers, or fibrils (Stromer and Serpell, 2005); in particular, increasing $A \beta$ tends to form monomers which aggregate into oligomers, prefibrillar assemblies (protofibrils) and amyloid fibrils in a concentration-dependent manner. Toxic $\mathrm{A} \beta$ peptides are formed by $36-43$ amino acids; the 42 amino acid peptide (AB42) is one of the most neurotoxic amyloidogenic fragment and represents the chief component of senile plaques. Increasing $A \beta$ level tends to form oligomers of different length and composition (Stromer and Serpell, 2005), which are toxic for neuronal cells (Origlia et al., 2008). In particular, $A \beta$ oligomeric extracts from cerebral cortex of AD patients (Shankar et al., 2008) and synthetic $A \beta$ formed by dimers and trimers (Origlia et al., 2008, 2009) are capable of inhibiting long term synaptic plasticity in the form of long term potentiation (LTP), 
which is involved in learning/memory in hippocampus and parahippocampal cortices (Nabavi et al., 2014); this represents an early step in the disease progression. Oligomeric $A \beta$ inhibits LTP through phosphorylation of p38 MAPK (Criscuolo et al., 2014). Increasing synthetic $A \beta$ concentration affects synaptic transmission, AMPA current (Origlia et al., 2010). Thus, accumulation of extracellular $A \beta$ is likely to result in progressive synaptic dysfunctions and cognitive impairment (Selkoe, 2002). Increasing $A \beta$ induces phosphorylation of MAPKs in neuronal and non-neuronal cells along with the induction of pro-inflammatory cytokines, such as the IL- $\beta$ (Origlia et al., 2010). Activation of receptors such as the receptor for advanced glycation end products (RAGE) by $\mathrm{A} \beta$ accounts for progress of synaptic dysfunction, development of inflammatory and, possibly, oxidative processes, leading cells to degenerate (Origlia et al., 2010).

The death of the RGCs in glaucoma is preceded by a remodeling of retinal circuitry, RGC dendritic arbor and axonal atrophy (Jakobs et al., 2005). Although it is not yet clear what initiates the death of RGCs in glaucoma, recent experimental evidence indicates that functional alterations caused by impairment of synapses (Della Santina et al., 2013) precede the degeneration of RGCs. A possible interpretation would be that the impairment of synapses is followed by consequences for RGC viability. Similarly to $A D$, enhanced retinal levels of soluble $\mathrm{A} \beta$ may act by impairing the synaptic circuitry and retrograde trafficking of neurotrophic factors in the ON axons (Poon et al., 2011; Gupta et al., 2014). Interestingly, high IOP, which characterizes an early reversible phase of retinal degeneration, leads to $A \beta$ induction (McKinnon et al., 2002). The hypothesis can be advanced that stressor stimuli such as the high IOP in glaucoma may cause accumulation of $A \beta$ in the retina, contributing to synaptic progressive dysfunction in the inner retina and impairment of visual responses. However, whether low amounts of $A \beta$ in the form of oligomers result in synaptic toxicity with detriment of visual retinal responses during ocular hypertension is still lacking. Concerning cell death, progressive degeneration of RGCs is associated with increased production of $\mathrm{A} \beta$ (McKinnon et al., 2002; Guo et al., 2007). Hence, it is assumed that $\mathrm{A} \beta$ leads not only to neuronal cell impairment in $\mathrm{AD}$ but also to retinal cell impairment and degeneration in glaucoma in general. Yan et al. (1996) showed that the RAGE activated by $A \beta$ is able to induce neuronal toxicity; it is known that oligomeric $A \beta$ induces phosphorylation of p38 MAPK through RAGE activation during an early phase of degeneration in $\mathrm{AD}$ (Origlia et al., 2008). Interestingly, hyperphosphorylation of p38 MAPK characterizes the degeneration of RGCs in glaucoma, mainly during an early phase with high IOP and synaptic dysfunction (Fabiani et al., 2016), whether RAGE is involved in the mechanisms of glaucoma onset and progression is still unanswered.

\section{TAU-DEPENDENT MECHANISMS IN AD AND GLAUCOMA}

The tau protein is expressed from the gene known as microtubule associated protein tau (MAPT) on chromosome 17. Tau is highly expressed in neurons and is abundant in axons (Lee et al., 2001). Tau facilitates assembly and the stabilization of microtubule polymers (Cleveland et al., 1977; Caceres and Kosik, 1990), modulating microtubule dynamics. Thus, under physiological conditions tau is mainly expressed within neurons. Hyperphosphorylated, insoluble and filamentous tau proteins were shown to be the main component of NFTs, a pathological hallmark of AD and other tauopathies (Lee et al., 2001). NFTs accumulate inside the cells, disrupting the intracellular transport system. Cytoskeletal changes are visible as dystrophic neurites, pre-tangles, NFTs in the cell bodies of affected neurons in AD (Iqbal et al., 1984). Interestingly, phosphorylation of tau potentiates MAPK activation similarly to $A \beta$ and tau is one of p38 MAPK substrates (Corrêa and Eales, 2012). Studies on cell viability have shown that misfolding of tau leads to the aggregation of tau and the appearance of toxic tau species in the extracellular space (Gómez-Ramos et al., 2006, 2008). The endogenous intracellular tau may be released as aggregates to the extracellular space upon neuron degeneration (Gómez-Ramos et al., 2006). Extracellular tau could be toxic by increasing intracellular calcium into neighboring neurons (Gómez-Ramos et al., 2008). The presence of extracellular tau can be due to other causes, for example exocytosis; the $\mathrm{N}$-terminal region of tau seems to be required for its secretion (Kim et al., 2010). Tau can also be released into the extracellular space, as oligomers (Saman et al., 2012). Indeed, neuronal toxicity may be caused by tau aggregates, even small and soluble aggregates in the form of oligomers, which have been identified in $\mathrm{AD}$ brains (Sahara et al., 2008). Recently, it has been shown that oligomeric extracellular tau is able to interact with cell receptors resulting in synaptic dysfunction and signaling propagation that could contribute to onset of neurodegeneration (Fá et al., 2016). These observations point to the involvement of extracellular tau aggregates as one of the main agent in the neuron-to-neuron propagation of neurofibrillary pathology and progression of toxicity in $\mathrm{AD}$.

Tau was found to be expressed in RGCs and it is involved in RGC axon development and survival (Lieven et al., 2007). In an aged retina there is an increase in the number of RGCs and photoreceptors expressing phosphorylated tau (Leger et al., 2011). In POAG with ocular hypertension, decreased total tau and increased phosphorylated tau was reported (Gupta et al., 2008). Hyperphosphorylation and aggregation of tau were associated in vivo with reduced axonal transport in the $\mathrm{ON}$ of transgenic mice line expressing human P301S tau transgene (Gasparini et al., 2011; Bull et al., 2012). However, whether intracellular and/or extracellular tau plays a role in glaucoma onset and progression is still an open question.

\section{NEW PERSPECTIVES ON THERAPEUTIC APPROACH}

Increasing lines of evidence suggest that aggregation and accumulation of $\mathrm{A} \beta$ and Tau eventually leading to MAPK phosphorylation represent common degenerative mechanisms in both $\mathrm{AD}$ and glaucomatous retinal degeneration. Determining 
the degenerative mechanisms is crucial for development of new therapeutics. The retina, which is affected in both diseases, can be an important brain area where to investigate common mechanisms also in view of new therapeutics. On this ground, a neuroprotective approach based on neurotrophic factors can be considered promising. Neuroprotection by neurotrophic factors was initially investigated for neurodegenerative diseases such as the $\mathrm{AD}$. Evidence suggests that treatments with neurotrophic factors such as the brain-derived neurotrophic factor (BDNF), ciliary neurotrophic factor (CNTF), glial cell line-derived neurotrophic factor (GDNF) increase the survival of neurons in animal models of injury and disease (Alqawlaq et al., 2012). BDNF, together with its receptor tropomyosin receptor kinase B (TrkB), is highly expressed in several brain areas under the control of neuronal activity (Castrén et al., 1992; Pattabiraman et al., 2005). BDNF acts by binding to the TrkB, activating downstream pathways including the MAPK, phosphatidylinositol kinase (PI3K) and phospholipase C- $\gamma$ (PLC- $\gamma$ ) signaling cascades (Kaplan and Miller, 2000). BDNF controls synaptic plasticity and cell survival in the visual system (Liu et al., 2007; Schwartz et al., 2011; Kimura et al., 2016). BDNF appears to provide the highest level of protection by supporting both protective and regenerative functions of RGCs in various models of ON injury and disease (Peinado-Ramón et al., 1996; Weber et al., 2008; Parrilla-Reverter et al., 2009). BDNF is locally produced by retinal cells in the ganglion cell and inner nuclear layers (Perez and Caminos, 1995); its TrkB receptor is expressed in RGCs, amacrine and Müller cells (Perez and Caminos, 1995; Cellerino and Kohler, 1997; Wahlin et al., 2001).

BDNF level is reduced in the glaucomatous retina (Pease et al., 2000; Quigley et al., 2000; Fabiani et al., 2016) as well as in several brain areas of AD (Connor et al., 1997; Michalski and Fahnestock, 2003; Peng et al., 2005), thus contributing to advancing the hypothesis that a scarce availability of BDNF renders neurons more vulnerable. In addition, BDNF is considered a peripheral marker of neurodegeneration. BDNF in the tears and/or blood is used for detection and assessment of neurodegenerative processes in POAG (Ghaffariyeh et al., 2009, 2011). The interpretation of the results obtained on $\mathrm{BDNF}$ level in blood (serum/plasma) of $\mathrm{AD}$ patients is more complex and contradictory (Komulainen et al., 2008; Faria et al., 2014). The idea is that cognitive deficits in $\mathrm{AD}$ are related to change of BDNF blood level as well as that of other neurotrophic factors such as the nerve growth factor and GDNF in blood (Budni et al., 2015). Interestingly, Yasutake et al. (2006) showed that there is a decline in blood BDNF once the disease has progressed to severe level. Thus, BDNF level in blood represents a marker of cognitive dysfunction and progress of neurodegeneration in $\mathrm{AD}$ and other neurodegenerative diseases such as Parkinson's disease (Scalzo et al., 2010) and vascular dementia (Yasutake et al., 2006).

BDNF is important for survival and plasticity of the RGCs in models of ON injury and disease (Peinado-Ramón et al., 1996; Weber et al., 2008; Parrilla-Reverter et al., 2009). BDNF delivery into the entorhinal cortex and hippocampus is able to ameliorate cognitive deficits in aging and experimental $\mathrm{AD}$ models (Nagahara et al., 2009). Thus, the reported results make BDNF a good candidate to drive full neuroprotective and repair strategies in neurodegenerative diseases, including glaucoma and $\mathrm{AD}$. However, the therapeutic approach based on BDNF is promising if the limits imposed by complex pharmacokinetic of high molecular weight proteins (for example BDNF low propensity to pass blood-brain and blood-ocular barriers following systemic treatment) are definitely defeated. Recently, we showed that BDNF topical eye treatment in the form of collyrium was able to increase the retinal level of BDNF up to rescue visual responses in a murine model of glaucoma (Domenici et al., 2014). Moreover, the intranasal delivery of proteins has recently emerged as a non-invasive and effective method to target high molecular weight proteins such as the BDNF to several brain areas (Alcalá-Barraza et al., 2010; Dhuria et al., 2010). Thus, BDNF non-invasive treatments represent a promising feasible therapeutic strategy to preserve neuronal function and diminish cell vulnerability in neurodegenerative diseases such as the $\mathrm{AD}$ and glaucoma. Although at present it is unclear how BDNF concentrations vary in vivo the use of high $\mathrm{BDNF}$ doses should be avoided to circumvent potential undesired effects such as the proconvulsant effects (Heinrich et al., 2011; Gu et al., 2015) and neovascularization (Lam et al., 2011). Additional therapeutic strategies based on BDNF have been used; these consist of gene delivery (Nagahara et al., 2013), transplantation of BDNF-expressing cell grafts (Kurozumi et al., 2005), TrkB agonists ( $\mathrm{Hu}$ et al., 2010; Devi and Ohno, 2012; Gu et al., 2015).

\section{CONCLUSION}

We reported that several common disease features appear in the $\mathrm{AD}$ and glaucoma. Based on common disease features that have been described here, several opportunities exist to develop common therapeutic strategies. A successful example involves neuroprotection by BDNF.

\section{AUTHOR CONTRIBUTIONS}

All authors listed, have made substantial, direct and intellectual contribution to the work, and approved its final version of the manuscript. LD conceived the review focus, conducted literature review and finalized the manuscript. CC summarized and finalized the manuscript. CF conducted literature review and finalized the manuscript. EC conducted literature review and finalized the manuscript.

\section{ACKNOWLEDGMENTS}

Supported by the Department of Biotechnological and Applied Clinical Sciences (DISCAB), University of L'Aquila, and the scientific consortium IN-BDNF. We thank Ms. S. Wilson for revising the English style. 


\section{REFERENCES}

Adzovic, L., and Domenici, L. (2014). Insulin induces phosphorylation of the AMPA receptor subunit GluR1, reversed by ZIP, and overexpression of protein kinase M zeta, reversed by amyloid beta. J. Neurochem. 131, 582-587. doi: $10.1111 /$ jnc. 12947

Alcalá-Barraza, S. R., Lee, M. S., Hanson, L. R., McDonald, A. A., Frey, W. H., and McLoon, L. K. (2010). Intranasal delivery of neurotrophic factors BDNF, CNTF, EPO, and NT-4 to the CNS. J. Drug Target. 18, 179-190. doi: 10.3109/10611860903318134

Alqawlaq, S., Huzil, J. T., Ivanova, M. V., and Foldvari, M. (2012). Challenges in neuroprotective nanomedicine development: progress towards noninvasive gene therapy of glaucoma. Nanomedicine (Lond) 7, 1067-1083. doi: $10.2217 / \mathrm{nnm} .12 .69$

Braak, H., and Braak, E. (1991). Demonstration of amyloid deposits and neurofibrillary changes in whole brain sections. Brain Pathol. 1, 213-216. doi: 10.1111/j.1750-3639.1991.tb00661.x

Braak, H., and Braak, E. (1993). Entorhinal-hippocampal interaction in mnestic disorders. Hippocampus 3, 239-246.

Budni, J., Bellettini-Santos, T., Mina, F., Garcez, L., and Zugno, A. Z. (2015). The involvement of BDNF, NGF and GDNF in aging and Alzheimer's disease. Aging Dis. 6, 331-341. doi: 10.14336/AD.2015.0825

Bull, N. D., Guidi, A., Goedert, M., Martin, K. R., and Spillantini, M. G. (2012). Reduced axonal transport and increased excitotoxic retinal ganglion cell degeneration in mice transgenic for human mutant P301S tau. PLoS One 7:e34724. doi: 10.1371/journal.pone.0034724

Caceres, A., and Kosik, K. S. (1990). Inhibition of neurite polarity by tau antisense oligonucleotides in primary cerebellar neurons. Nature 343, 461-463. doi: 10.1038/343461a0

Castrén, E., Zafra, F., Thoenen, H., and Lindholm, D. (1992). Light regulates expression of brain-derived neurotrophic factor mRNA in rat visual cortex. Proc. Natl. Acad. Sci. U S A 89, 9444-9448. doi: 10.1073/pnas.89. 20.9444

Cellerino, A., and Kohler, K. (1997). Brain-derived neurotrophic factor/neurotrophin-4 receptor TrkB is localized on ganglion cells and dopaminergic amacrine cells in the vertebrate retina. J. Comp. Neurol. 386, 149-160. doi: 10.1002/(SICI)1096-9861(19970915)386:1<149::AID-CNE13>3. 3.CO;2-X

Chandra, V., Bharucha, N. E., and Schoenberg, B. S. (1986). Conditions associated with Alzheimer's disease at death: case-control study. Neurology 36, 209-211. doi: 10.1212/wnl.36.2.209

Cleveland, D. W., Hwo, S. Y., and Kirschner, M. W. (1977). Purification of tau, a microtubule-associated protein that induces assembly of microtubules from purified tubulin. J. Mol. Biol. 116, 207-225. doi: 10.1016/0022-2836(77) 90213-3

Coleman, A. L., and Brigatti, L. (2001). The glaucomas. Minerva Med. 92, 365-379.

Connor, B., Young, D., Yan, Q., Faull, R. L. M., Synek, B., and Dragunow, M. (1997). Brain-derived neurotrophic factor is reduced in Alzheimer's disease. Mol. Brain Res. 49, 71-81. doi: 10.1016/s0169-328x(97)00125-3

Corrêa, S. A. L., and Eales, K. L. (2012). The role of p38 MAPK and its substrates in neuronal plasticity and neurodegenerative disease. J. Signal Transduct. 2012:64907. doi: 10.1155/2012/649079

Criscuolo, C., Fabiani, C., Bonadonna, C., Origlia, N., and Domenici, L. (2014). BDNF prevents amyloid-dependent impairment of LTP in the entorhinal cortex by attenuating p38 MAPK phosphorylation. Neurobiol. Aging 36, 1303-1309. doi: 10.1016/j.neurobiolaging.2014.11.016

Crow, R. W., Levin, L. B., LaBree, L., Rubin, R., and Feldon, S. E. (2003). Sweep visual evoked potential evaluation of contrast sensitivity in Alzheimer's dementia. Invest. Ophthalmol. Vis. Sci. 44, 875-878. doi: 10.1167/iovs. 01-1101

Della Santina, L., Inman, D. M., Lupien, C. B., Horner, P. J., and Wong, R. O. (2013). Differential progression of structural and functional alterations in distinct retinal ganglion cell types in a mouse model of glaucoma. J. Neurosci. 33, 17444-17457. doi: 10.1523/JNEUROSCI.5461-12.2013

Devi, L., and Ohno, M. (2012). 7,8-Dihydroxyflavone, a small-molecule TrkB agonist, reverses memory deficits and BACE1 elevation in a mouse model of Alzheimer's disease. Neuropsychopharmacology 37, 434-444. doi: 10.1038/npp. 2011.191
Dhuria, S. V., Hanson, L. R., and Frey, W. H. (2010). Intranasal delivery to the central nervous system: mechanisms and experimental considerations. J. Pharm. Sci. 99, 1654-1673. doi: 10.1002/jps.21924

Domenici, L., Origlia, N., Falsini, B., Cerri, E., Barloscio, D., Fabiani, C., et al. (2014). Rescue of retinal function by BDNF in a mouse model of glaucoma. PLoS One 9:e115579. doi: 10.1371/journal.pone.0115579

Elyashiv, S. M., Shabtai, E. L., and Belkin, M. (2014). Correlation between visual acuity and cognitive functions. Br. J. Ophthalmol. 98, 129-132. doi: 10.1136/bjophthalmol-2013-304149

Fá, M., Puzzo, D., Piacentini, R., Staniszewski, A., Zhang, H., Baltrons, M. A., et al. (2016). Extracellular Tau oligomers produce an immediate impairment of LTP and memory. Sci. Rep. 6:19393. doi: 10.1038/srep19393

Fabiani, C., Cerri, E., Ottino, S., Sansò, M., and Domenici, L. (2016). Changes in BDNF and MAPK signaling pathways in experimental glaucoma. J. Clin. Exp. Ophthalmol. 7, 530. doi: 10.4172/2155-9570.1000530

Faria, M. C., Gonçalves, G. S., Rocha, N. P., Moraes, E. N., Bicalho, M. A., Gualberto Cintra, M. T., et al. (2014). Increased plasma levels of BDNF and inflammatory markers in Alzheimer's disease. J. Psychiatr. Res. 53, 166-172. doi: 10.1016/j.jpsychires.2014.01.019

Gasparini, L., Crowther, R. A., Martin, K. R., Berg, N., Coleman, M., Goedert, M., et al. (2011). Tau inclusions in retinal ganglion cells of human P301S tau transgenic mice: effects on axonal viability. Neurobiol. Aging 32, 419-433. doi: 10.1016/j.neurobiolaging.2009.03.002

Ghaffariyeh, A., Honarpisheh, N., Heidari, M. H., Puyan, S., and Abasov, F. (2011). Brain-derived neurotrophic factor as a biomarker in primary open-angle glaucoma. Optom. Vis. Sci. 88, 80-85. doi: 10.1097/opx.0b013e3181fc329f

Ghaffariyeh, A., Honarpisheh, N., Shakiba, Y., Puyan, S., Chamacham, T., Zahedi, F., et al. (2009). Brain-derived neurotrophic factor in patients with normal-tension glaucoma. Optometry 80, 635-638. doi: 10.1016/j.optm.2008. 09.014

Gómez-Ramos, A., Díaz-Hernández, M., Cuadros, R., Hernández, F., and Avila, J. (2006). Extracellular tau is toxic to neuronal cells. FEBS Lett. 580, 4842-4850. doi: 10.1016/j.febslet.2006.07.078

Gómez-Ramos, A., Díaz-Hernández, M., Rubio, A., Miras-Portugal, M. T., and Avila, J. (2008). Extracellular tau promotes intracellular calcium increase through M1 and M3 muscarinic receptors in neuronal cells. Mol. Cell. Neurosci. 37, 673-681. doi: 10.1016/j.mcn.2007.12.010

Graw, J. (2015). From eyeless to neurological diseases. Exp. Eye Res. doi: 10.1016/j. exer.2015.11.006 [Epub ahead of print].

Gu, B., Huang, Y. Z., He, X. P., Joshi, R. B., Jang, W., and McNamara, J. O. (2015). A peptide uncoupling BDNF receptor TrkB from phospholipase $C \gamma 1$ prevents epilepsy induced by status epilepticus. Neuron 88, 484-491. doi: 10.1016/j. neuron.2015.09.032

Guo, L., Salt, T. E., Luong, V., Wood, N., Cheung, W., Maass, A., et al. (2007). Targeting amyloid- $\beta$ in glaucoma treatment. Proc. Natl. Acad. Sci. U S A 14, 13444-13449. doi: 10.1073/pnas.0703707104

Gupta, N., Fong, J., Ang, L. C., and Yücel, Y. H. (2008). Retinal tau pathology in human glaucomas. Can. J. Ophthalmol. 43, 53-60. doi: 10.3129/ i07-185

Gupta, V., You, Y., Li, J., Gupta, V., Golzan, M., Klistorner, A., et al. (2014). BDNF impairment is associated with age-related changes in the inner retina and exacerbates experimental glaucoma. Biochim. Biophys. Acta 1842, 1567-1578. doi: 10.1016/j.bbadis.2014.05.026

Heinrich, C., Lähteinen, S., Suzuki, F., Anne-Marie, L., Huber, S., Häussler, U., et al. (2011). Increase in BDNF-mediated TrkB signaling promotes epileptogenesis in a mouse model of mesial temporal lobe epilepsy. Neurobiol. Dis. 42, 35-47. doi: 10.1016/j.nbd.2011.01.001

Hirai, K., Aliev, G., Nunomura, A., Fujioka, H., Russell, R. L., Atwood, C. S., et al. (2001). Mitochondrial abnormalities in Alzheimer's disease. J. Neurosci. 21, 3017-3023.

Hu, Y., Cho, S., and Goldberg, J. L. (2010). Neurotrophic effect of a novel TrkB agonist on retinal ganglion cells. Invest. Ophthalmol. Vis. Sci. 51, 1747-1754. doi: 10.1167/iovs.09-4450

Iqbal, K., Zaidi, T., Thompson, C. H., Merz, P. A., and Wisniewski, H. M. (1984). Alzheimer paired helical filaments: bulk isolation, solubility, and protein composition. Acta Neuropathol. 62, 167-177. doi: 10.1007/bf00691849

Jakobs, T. C., Libby, R. T., Ben, Y., John, S. W., and Masland, R. H. (2005). Retinal ganglion cell degeneration is topological but not cell type 
specific in DBA/2J mice. J. Cell Biol. 171, 313-325. doi: 10.1083/jcb.2005 06099

Jefferis, J. M., Taylor, J. P., Collerton, J., Jagger, C., Kingston, A., Davies, K., et al. (2013). The association between diagnosed glaucoma and cataract and cognitive performance in very old people: cross-sectional findings from the newcastle 85+ study. Ophthalmic Epidemiol. 20, 82-88. doi: 10.3109/09286586. 2012.757626

Kaplan, D. R., and Miller, F. D. (2000). Neurotrophin signal transduction in the nervous system. Curr. Opin. Neurobiol. 10, 381-391. doi: 10.1016/s09594388(00)00092-1

Kessing, L. V., Lopez, A. G., Andersen, P. K., and Kessing, S. V. (2007). No increased risk of developing Alzheimer disease in patients with glaucoma. J. Glaucoma 16, 47-51. doi: 10.1097/ijg.0b013e31802b3527

Kim, W., Lee, S., Jung, C., Ahmed, A., Lee, G., and Hall, G. F. (2010). Interneuronal transfer of human tau between Lamprey central neurons in situ. J. Alzheimers Dis. 19, 647-664. doi: 10.3233/JAD-2010-1273

Kimura, A., Namekata, K., Guo, X., Harada, C., and Harada, T. (2016). Neuroprotection, growth factors and BDNF-TrkB signalling in retinal degeneration. Int. J. Mol. Sci. 17:1584. doi: 10.3390/ijms17091584

Komulainen, P., Pedersen, M., Hänninen, T., Bruunsgaard, H., Lakka, T. A., Kivipelto, M., et al. (2008). BDNF is a novel marker of cognitive function in ageing women: the DR's EXTRA Study. Neurobiol. Learn. Mem. 90, 596-603. doi: 10.1016/j.nlm.2008.07.014

Kurozumi, K., Nakamura, K., Tamiya, T., Kawano, Y., Ishii, K., Kobune, M., et al. (2005). Mesenchymal stem cells that produce neurotrophic factors reduce ischemic damage in the rat middle cerebral artery occlusion model. Mol. Ther. 11, 96-104. doi: 10.1016/j.ymthe.2004.09.020

Lam, C. T., Yang, Z. F., Lau, C. K., Tam, K. H., Fan, S. T., and Poon, R. T. P. (2011). Brain-derived neurotrophic factor promotes tumorigenesis via induction of neovascularization: implication in hepatocellular carcinoma. Clin. Cancer Res. 17, 3123-3133. doi: 10.1158/1078-0432.ccr-10-2802

Lee, V. M.-Y., Goedert, M., and Trojanowski, J. Q. (2001). Neurodegenerative tauopathies. Annu. Rev. Neurosci. 24, 1121-1159. doi: 10.1146/annurev.neuro. 24.1.1121

Leger, F., Fernagut, P. O., Canron, M. H., Léoni, S., Vital, C., Tison, F., et al. (2011). Protein aggregation in the aging retina. J. Neuropathol. Exp. Neurol. 70, 63-68. doi: 10.1097/NEN.0b013e31820376cc

Lieven, C. J., Millet, L. E., Hoegger, M. J., and Levin, L. A. (2007). Induction of axon and dendrite formation during early RGC-5 cell differentiation. Exp. Eye Res. 85, 678-683. doi: 10.1016/j.exer.2007.08.001

Liu, X., Grishanin, R. N., Tolwani, R. J., Rentería, R. C., Xu, B., Reichardt, L. F., et al. (2007). Brain-derived neurotrophic factor and TrkB modulate visual experience-dependent refinement of neuronal pathways in retina. J. Neurosci. 4, 7256-7267. doi: 10.1523/JNEUROSCI.0779-07.2007

Liu, C. C., Kanekiyo, T., Xu, H., and Bu, G. (2013). Apolipoprotein E and Alzheimer disease: risk, mechanisms and therapy. Nat. Rev. Neurol. 9, 106-118. doi: 10.1038/nrneurol.2012.263

Martinez, G. S., Campbell, A. J., Reinken, J., and Allan, B. C. (1982). Prevalence of ocular disease in a population study of subjects 65 years old and older. Am. J. Ophthalmol. 94, 181-189. doi: 10.1016/0002-9394(82)90073-3

Mayeux, R., and Stern, Y. (2012). Epidemiology of Alzheimer disease. Cold Spring Harb. Perspect. Med. 2:a006239. doi: 10.1101/cshperspect.a006239

McKinnon, S. J., Lehman, D. M., Kerrigan-Baumrind, L. A., Merges, C. A., Pease, M. E., Kerrigan, D. F., et al. (2002). Caspase activation and amyloid precursor protein cleavage in rat ocular hypertension. Invest. Ophthalmol. Vis. Sci. 43, 1077-1087.

Michalski, B., and Fahnestock, M. (2003). Pro-brain-derived neurotrophic factor is decreased in parietal cortex in Alzheimer's disease. Mol. Brain Res. 111, 148-154. doi: 10.1016/s0169-328x(03)00003-2

Moschos, M. M., Markopoulos, I., Chatziralli, I., Rouvas, A., Papageorgiou, S. G., Ladas, I., et al. (2012). Structural and functional impairment of the retina and optic nerve in Alzheimer's disease. Curr. Alzheimer Res. 9, 782-788. doi: 10.2174/156720512802455340

Nabavi, S., Fox, R., Proulx, C. D., Lin, J. Y., Tsien, R. Y., and Malinow, R. (2014). Engineering a memory with LTD and LTP. Nature 511, 348-352. doi: 10.1038/nature13294

Nagahara, A. H., Mateling, M., Kovacs, I., Wang, L., Eggert, S., Rockenstein, E., et al. (2013). Early BDNF treatment ameliorates cell loss in the entorhinal cortex of APP transgenic mice. J. Neurosci. 33, 15596-15602. doi: 10.1523/JNEUROSCI.5195-12.2013

Nagahara, A. H., Merrill, D. A., Coppola, G., Tsukada, S., Schroeder, B. E., Shaked, G. M., et al. (2009). Neuroprotective effects of brain-derived neurotrophic factor in rodent and primate models of Alzheimer's disease. Nat. Med. 15, 331-337. doi: 10.1038/nm.1912

Origlia, N., Bonadonna, C., Rosellini, A., Leznik, E., Arancio, O., Yan, S. S.-D., et al. (2010). Microglial RAGE-dependent signal pathway drives A $\beta$-induced synaptic depression and long-term depression impairment in entorhinal cortex. J. Neurosci. 30, 11414-11425. doi: 10.1523/JNEUROSCI.212710.2010

Origlia, N., Capsoni, S., Cattaneo, A., Fang, F., Arancio, O., Yan, S. D., et al. (2009). $\mathrm{A} \beta$-dependent inhibition of LTP in different intra-cortical circuits of the visual cortex: the role of RAGE. J. Alzheimers Dis. 17, 59-68. doi: 10.3233/JAD2009-1045

Origlia, N., Criscuolo, C., Arancio, O., Yan, S. S., and Domenici, L. (2014). RAGE inhibition in microglia prevents ischemia-dependent synaptic dysfunction in an amyloid-enriched environment. J. Neurosci. 34, 8749-8760. doi: 10.1523/JNEUROSCI.0141-14.2014

Origlia, N., Righi, M., Capsoni, S., Cattaneo, A., Fang, F., Stern, D. M., et al. (2008). Receptor for advanced glycation endproducts (RAGE)dependent activation of p38 mitogen-activated protein kinase contributes to amyloid $\beta$-mediated cortical synaptic dysfunction. J. Neurosci. 28, 3521-3530. doi: 10.1523/JNEUROSCI.0204-08.2008

Parrilla-Reverter, G., Agudo, M., Sobrado-Calvo, P., Salinas-Navarro, M., VillegasPérez, M. P., and Vidal-Sanz, M. (2009). Effects of different neurotrophic factors on the survival of retinal ganglion cells after a complete intraorbital nerve crush injury: a quantitative in vivo study. Exp. Eye Res. 89, 32-41. doi: 10.1016/j.exer.2009.02.015

Pattabiraman, P. P., Tropea, D., Chiaruttini, C., Tongiorgi, E., Cattaneo, A., and Domenici, L. (2005). Neuronal activity regulates the developmental expression and subcellular localization of cortical BDNF mRNA isoforms in vivo. Mol. Cell. Neurosci. 28, 556-570. doi: 10.1016/j.mcn.2004.11.010

Pease, M. E., McKinnon, S. J., Quigley, H. A., Kerrigan-Baumrind, L. A., and Zack, D. J. (2000). Obstructed axonal transport of BDNF and its receptor TrkB in experimental glaucoma. Invest. Ophthalmol. Vis. Sci. 41, 764-774.

Peinado-Ramón, P., Salvador, M., Villegas-Pérez, M. P., and Vidal-Sanz, M. (1996). Effects of axotomy and intraocular administration of NT-4, NT-3, and brain-derived neurotrophic factor on the survival of adult rat retinal ganglion cells. A quantitative in vivo study. Invest. Ophthalmol. Vis. Sci. 37, 489-500.

Peng, S., Wuu, J., Mufson, E. J., and Fahnestock, M. (2005). Precursor form of brain-derived neurotrophic factor and mature brain-derived neurotrophic factor are decreased in the pre-clinical stages of Alzheimer's disease. J. Neurochem. 93, 1412-1421. doi: 10.1111/j.1471-4159.2005. 03135.x

Perez, M.-T. R., and Caminos, E. (1995). Expression of brain-derived neurotrophic factor and of its functional receptor in neonatal and adult rat retina. Neurosci. Lett. 183, 96-99. doi: 10.1016/0304-3940(94)11123-Z

Pluta, R., Jabłonski, M., Ułamek-Kozioł, M., Kocki, J., Brzozowska, J., Januszewski, S., et al. (2013). Sporadic Alzheimer's disease begins as episodes of brain ischemia and ischemically dysregulated Alzheimer's disease genes. Mol. Neurobiol. 48, 500-515. doi: 10.1007/s12035-013-8439-1

Poon, W. W., Blurton-Jones, M., Tu, C. H., Feinberg, L. M., Chabrier, M. A., Harris, J. W., et al. (2011). $\beta$-Amyloid impairs axonal BDNF retrograde trafficking. Neurobiol. Aging 32, 821-833. doi: 10.1016/j.neurobiolaging.2009. 05.012

Quigley, H. A. (2011). Glaucoma. Lancet 377, 1367-1377. doi: 10.1016/S01406736(10)61423-7

Quigley, H. A., and Broman, A. T. (2006). The number of people with glaucoma worldwide in 2010 and 2020. Br. J. Ophthalmol. 90, 262-267. doi: 10.1136/bjo. 2005.081224

Quigley, H. A., McKinnon, S. J., Zack, D. J., Pease, M. E., KerriganBaumrind, L. A., Kerrigan, D. F., et al. (2000). Retrograde axonal transport of $\mathrm{BDNF}$ in retinal ganglion cells is blocked by acute IOP elevation in rats. Invest. Ophthalmol. Vis. Sci. 41, 3460-3466.

Reitz, C., and Mayeux, R. (2014). Alzheimer disease: epidemiology, diagnostic criteria, risk factors and biomarkers. Biochem. Pharmacol. 88, 640-651. doi: 10.1016/j.bcp.2013.12.024 
Rizzo, M., Anderson, S. W., Dawson, J., and Nawrot, M. (2000). Vision and cognition in Alzheimer's disease. Neuropsychologia 38, 1157-1169. doi: 10.1016/S0028-3932(00)00023-3

Sahara, N., Maeda, S., and Takashima, A. (2008). Tau oligomerization: a role for tau aggregation intermediates linked to neurodegeneration. Curr. Alzheimer Res. 5, 591-598. doi: 10.2174/156720508786898442

Saman, S., Kim, W., Raya, M., Visnick, Y., Miro, S., Saman, S., et al. (2012). Exosome-associated tau is secreted in tauopathy models and is selectively phosphorylated in cerebrospinal fluid in early Alzheimer disease. J. Biol. Chem. 287, 3842-3849. doi: 10.1074/jbc.M111.277061

Sartucci, F., Borghetti, D., Bocci, T., Murri, L., Orsini, P., Porciatti, V., et al. (2010). Dysfunction of the magnocellular stream in Alzheimer's disease evaluated by pattern electroretinograms and visual evoked potentials. Brain Res. Bull. 82, 169-176. doi: 10.1016/j.brainresbull.2010.04.001

Scalzo, P., Kümmer, A., Bretas, T. L., Cardoso, F., and Teixeira, A. L. (2010). Serum levels of brain-derived neurotrophic factor correlate with motor impairment in Parkinson's disease. J. Neurol. 257, 540-545. doi: 10.1007/s00415-0095357-2

Schwartz, N., Schohl, A., and Ruthazer, E. S. (2011). Activity-dependent transcription of BDNF enhances visual acuity during development. Neuron 70, 455-467. doi: 10.1016/j.neuron.2011.02.055

Selkoe, D. J. (2002). Alzheimer's disease is a synaptic failure. Science 298, 789-791. doi: $10.1126 /$ science. 1074069

Serrano-Pozo, A., Frosch, M. P., Masliah, E., and Hyman, B. T. (2011). Neuropathological alterations in Alzheimer disease. Cold Spring Harb. Perspect. Med. 1:a006189. doi: 10.1101/cshperspect.a006189

Shankar, G. M., Li, S., Mehta, T. H., Garcia-Munoz, A., Shepardson, N. E., Smith, I., et al. (2008). Amyloid- $\beta$ protein dimers isolated directly from Alzheimer's brains impair synaptic plasticity and memory. Nat. Med. 14, 837-842. doi: 10.1038/nm1782

Sivak, J. M. (2013). The aging eye: common degenerative mechanisms between the Alzheimer's brain and retinal disease. Invest. Ophthalmol. Vis. Sci. 54, 871-880. doi: $10.1167 /$ iovs. $12-10827$

Stromer, T., and Serpell, L. C. (2005). Structure and morphology of the Alzheimer's amyloid fibril. Microsc. Res. Tech. 67, 210-217. doi: 10.1002/jemt.20190

Tamura, H., Kawakami, H., Kanamoto, T., Kato, T., Yokoyama, T., Sasaki, K., et al. (2006). High frequency of open-angle glaucoma in Japanese patients with Alzheimer's disease. J. Neurol. Sci. 246, 79-83. doi: 10.1016/j.jns.2006.02.009

Tanzi, R. E. (2012). The genetics of Alzheimer disease. Cold Spring Harb. Perspect. Med. 2:a006296. doi: 10.1101/cshperspect.a006296

Tsolaki, F., Gogaki, E., Tiganita, S., Skatharoudi, C., Lopatatzidi, C., Topouzis, F., et al. (2011). Alzheimer's disease and primary open-angle glaucoma: is there a connection? Clin. Ophthalmol. 5, 887-890. doi: 10.2147/OPTH.S22485
Tsuno, N., and Homma, A. (2009). What is the association between depression and Alzheimer's disease? Expert Rev. Neurother. 9, 1667-1676. doi: 10.1586/ern. 09.106

Van Den Heuvel, C., Thornton, E., and Vink, R. (2007). Traumatic brain injury and Alzheimer's disease: a review. Prog. Brain Res. 161, 303-316. doi: 10.1016/S0079-6123(06)61021-2

Wahlin, K. J., Adler, R., Zack, D. J., and Campochiaro, P. A. (2001). Neurotrophic signaling in normal and degenerating rodent retinas. Exp. Eye Res. 73, 693-701. doi: 10.1006/exer.2001.1078

Weber, A. J., Harman, C. D., and Viswanathan, S. (2008). Effects of optic nerve injury, glaucoma, and neuroprotection on the survival, structure, and function of ganglion cells in the mammalian retina. J. Physiol. 586, 4393-4400. doi: 10.1113/jphysiol.2008.156729

Yamasaki, T., Horie, S., Ohyagi, Y., Tanaka, E., Nakamura, N., Goto, Y., et al. (2016). A potential VEP biomarker for mild cognitive impairment: evidence from selective visual deficit of higher-level dorsal pathway. J. Alzheimers Dis. 53, 661-676. doi: 10.3233/JAD-150939

Yan, S. D., Chen, X., Fu, J., Chen, M., Zhu, H., Roher, A., et al. (1996). RAGE and amyloid-beta peptide neurotoxicity in Alzheimer's disease. Nature 382, 685-691. doi: 10.1038/382685a0

Yasutake, C., Kuroda, K., Yanagawa, T., Okamura, T., and Yoneda, H. (2006). Serum BDNF, TNF- $\alpha$ and IL-1 $\beta$ levels in dementia patients: comparison between Alzheimer's disease and vascular dementia. Eur. Arch. Psychiatry Clin. Neurosci. 256, 402-406. doi: 10.1007/s00406-006-0652-8

Yochim, B. P., Mueller, A. E., Kane, K. D., and Kahook, M. Y. (2012). Prevalence of cognitive impairment, depression, and anxiety symptoms among older adults with glaucoma. J. Glaucoma 21, 250-254. doi: 10.1097/IJG.0b013e31820 $71 \mathrm{~b} 7 \mathrm{e}$

Zhao, W. Q., De Felice, F. G., Fernandez, S., Chen, H., Lambert, M. P., Quon, M. J., et al. (2008). Amyloid beta oligomers induce impairment of neuronal insulin receptors. FASEB J. 22, 246-260. doi: 10.1096/fj.06-7703com

Conflict of Interest Statement: The authors declare that the research was conducted in the absence of any commercial or financial relationships that could be construed as a potential conflict of interest.

Copyright (C) 2017 Criscuolo, Fabiani, Cerri and Domenici. This is an open-access article distributed under the terms of the Creative Commons Attribution License (CC BY). The use, distribution and reproduction in other forums is permitted, provided the original author(s) or licensor are credited and that the original publication in this journal is cited, in accordance with accepted academic practice. No use, distribution or reproduction is permitted which does not comply with these terms. 